\title{
Femtosecond Laser-Assisted Etching of Fluoride Crystals
}

\author{
Shigeki Matsuo ${ }^{* 1}$, Kodai Iwasa ${ }^{* 1}$, Takuro Tomita ${ }^{* 1}$, Shuichi Hashimoto ${ }^{* 1}$, Tatsuya Okada ${ }^{* 2}$ \\ ${ }^{* 1}$ Department of Ecosystem Engineering, The University of Tokushima, \\ 2-1 Minamijosanjimacho, Tokushima 770-8506, Japan. \\ E-mail: matsuos@eco.tokushima-u.ac.jp \\ *2 Department of Mechanical Engineering, The University of Tokushima, \\ 2-1 Minamijosanjimacho, Tokushima 770-8506, Japan.
}

\begin{abstract}
Femtosecond laser-assisted etching is a technique for internal micro removal processing of transparent materials. In the present study, we applied this technique to fluoride crystals of $\mathrm{CaF}_{2}$ and $\mathrm{MgF}_{2}$. In the case of $\mathrm{CaF}_{2}$, selective etching of a femtosecond laser-modified region was observed with etchants of aqueous solutions of nitric acid, sulfuric acid, and hydrogen chloride, while no signature of etching was observed for $\mathrm{MgF}_{2}$. Microchannels were fabricated in $\mathrm{CaF}_{2}$ substrates. At the inlet, the microchannel showed polygonal shapes, which may be related to anisotropy in the etching rate.
\end{abstract}

DOI:10.2961/jlmn.2011.03.0014

Keywords: Femtosecond laser-assisted etching, micromachining, fluoride, $\mathrm{CaF}_{2}, \mathrm{MgF}_{2}$

\section{Introduction}

Femtosecond (fs) lasers have made possible new fields of material processing. A unique feature of fs laser processing is the possibility to modify the inside of a material without damaging its surface [1]. By combining fs laser modification inside a material with selective chemical etching of the modified region, we can carry out micro removal processing inside transparent solids, a process we call fs laser-assisted etching [2]. Because of the threedimensional (3D) capability of fs laser modification, we can make empty regions with 3D arbitrariness in design, for example, microchannels and microcavities. This technique was first reported in a photosensitive glass [3] and then in a nonphotosensitive material of silica glass [4]. Research on this topic has been reported from both basic and application points of view [5-10].

In the present study, we examined the applicability of fs laser-assisted etching to fluoride crystals, whereas previous studies have treated only oxides. Fluoride crystals such as calcium fluoride $\left(\mathrm{CaF}_{2}\right)$, magnesium fluoride $\left(\mathrm{MgF}_{2}\right)$, lithium fluoride $(\mathrm{LiF})$, and barium fluoride $\left(\mathrm{BaF}_{2}\right)$ are known as transparent materials in the wide wavelength range, from infrared (IR) to deep ultraviolet (DUV). Accordingly, they are used as, for example, windows and lenses, especially in the DUV region [11]. Among these materials, $\mathrm{CaF}_{2}$ and $\mathrm{MgF}_{2}$ have the advantages of low solubility in water (low deliquescence character), and thus they are usable in ambient atmosphere. $\mathrm{CaF}_{2}$ is the dominant optical material in ArF excimer laser optics $[11,12] . \mathrm{MgF}_{2}$ has a wider transparent wavelength region in DUV than that of $\mathrm{CaF}_{2}$. Thus we used $\mathrm{CaF}_{2}$ and $\mathrm{MgF}_{2}$ crystalline substrates in the present study. Processing inside these materials will allow us to make micro analysis chips using UV light.

\section{Experimental Procedure}

Crystalline substrates of $\mathrm{CaF}_{2}$ and $\mathrm{MgF}_{2}$ were supplied as $10 \times 10 \times 0.5 \mathrm{~mm}$ samples that were double-side polished by Ohyo Koken Kogyo Co., Ltd. For $\mathrm{CaF}_{2}$, (111)

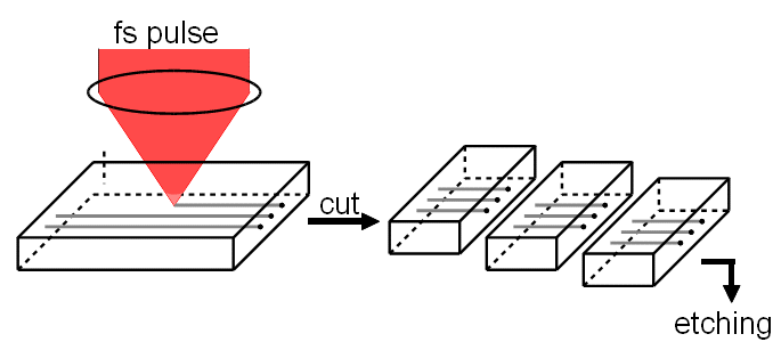

Fig. 1 Scheme of fs laser modification and sample preparation for etching.

and (110) substrates were used. For $\mathrm{MgF}_{2}$, the crystal plane was not specified.

A Ti:Sapphire fs regenerative amplifier (Spitfire, Spectra-Physics) was used as a fs light source. Fs laser pulses were led to an inverted optical microscope, reflected by a dichroic mirror, and irradiated to the sample through an objective lens $(40 \mathrm{x}, \mathrm{NA}=0.55)$. During irradiation, the sample was scanned using a 3D motorized stage, so that modified lines consisting of modified spots were written. The pulse energy was varied from 0.25 to $2 \mu \mathrm{J}$ measured before the microscope, and the pitch (the distance between neighboring modified spots) was varied from 0.1 to $2 \mu \mathrm{m}$. The fs laser pulse was lineally polarized, and its electric field was parallel to the modified lines.

After laser irradiation, the substrates were cut using a wire saw so that modified lines had an end on an end facet (see Fig. 1). The etching along the modified lines started from this end facet. This ruled out any undesirable edge effect [13] during fs laser irradiation.

After etching, the substrates were cleaned and immersed in etchant. The etchants used were three kinds of acid, aqueous solutions of nitric acid $\left(\mathrm{HNO}_{3}\right)$, sulfuric acid $\left(\mathrm{H}_{2} \mathrm{SO}_{4}\right)$, and hydrogen chloride $(\mathrm{HCl})$ at concentrations of 0.05 and $0.5 \mathrm{M}\left(\mathrm{M}=\mathrm{mol} / \mathrm{dm}^{3}\right)$. Etching was carried out at room temperature. The samples were observed by optical microscopy during and after etching, and the etched distance was evaluated. 


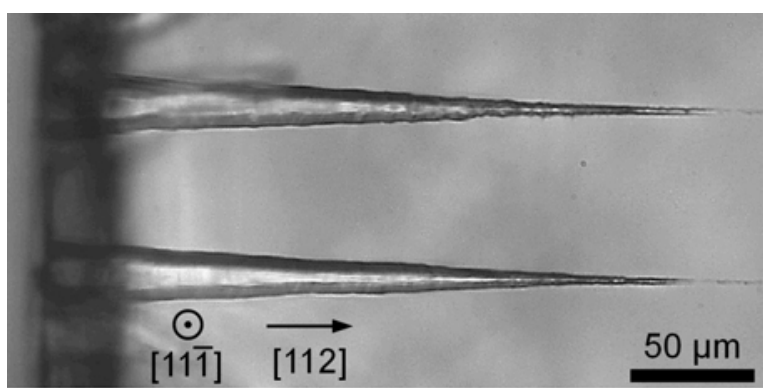

Fig. 2 Optical micrograph of microchannels along the $<112>$ direction in $\mathrm{a} \mathrm{CaF}_{2}$ (111) substrate (top view of the substrate, side view of the microchannel). The irradiated fs pulse energy was $0.5 \mu \mathrm{J}$, and the pitch was 0.1 $\mu \mathrm{m}$ (top) and $0.25 \mu \mathrm{m}$ (bottom). The etching was carried out in $0.5 \mathrm{M}$ nitric acid for 27 hours at room temperature.

\section{Results and Discussion}

Fs laser writing of modified lines was possible for both $\mathrm{CaF}_{2}$ and $\mathrm{MgF}_{2}$ substrates with the pulse energies and pitches used, except for a pulse energy of $0.25 \mu \mathrm{J}$ and a pitch of $0.25 \mu \mathrm{m}$ or more. However, no signature of etching was observed in either the modified or unmodified regions of $\mathrm{MgF}_{2}$. This may be because the fs laser irradiation applied in the present study was not enough to overcome the good resistance to chemical etching of pristine $\mathrm{MgF}_{2}$ crystal. In the following, we describe the results obtained on $\mathrm{CaF}_{2}$ only.

A typical optical micrograph of $\mathrm{CaF}_{2}$ after wet etching is shown in Fig. 2. Color change regions with a sharp cone shape can be seen on the modified lines along the $<112>$ direction. The color change along the irradiated region indicates that the region was etched out, that is, material along the line was selectively removed and microchannels were formed. However, the diameters were not homogeneous; the deeper the microchannel, the narrower it was. The etching selectivity (as determined by the ratio of etching rate between modified and un-modified regions) was evaluated by dividing the etched length by the radius on the end facet. The obtained value was about 20; this value is not very good compared to those obtained previously for other materials $[2,14,15]$.

In Fig. 3, the etched length was plotted as a function of time for three etchants. $\mathrm{HCl}$ and $\mathrm{HNO}_{3}$ showed similar

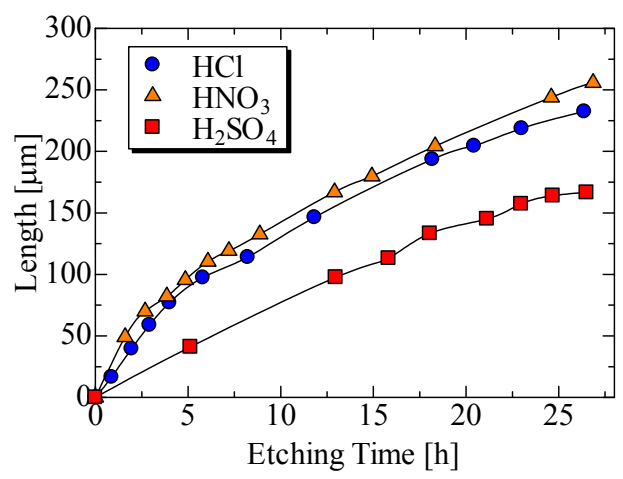

Fig. 3 Etched length as a function of etching time for three etchants at a concentration of $0.5 \mathrm{M}$. The substrates used were $\mathrm{CaF}_{2}$ (111), and the modified lines were along the $<112>$ direction. The irradiated pulse energy was $1.0 \mu \mathrm{J}$, and the pitch was $0.5 \mu \mathrm{m}$. results, while $\mathrm{H}_{2} \mathrm{SO}_{4}$ showed shorter etched length. Interestingly, the etching rate of $\mathrm{H}_{2} \mathrm{SO}_{4}$ showed a weaker dependence on the concentration. At the lower concentration of $0.05 \mathrm{M}$, the etching rate in $\mathrm{H}_{2} \mathrm{SO}_{4}$ was faster than those in the other etchants.

In Fig. 4, the etched length was plotted as a function of pitch for three etchants. The results with $\mathrm{HCl}$ and $\mathrm{HNO}_{3}$ showed a similar tendency. The etched length was independent of pitch at a higher pulse energy, and the etched length decreased with increasing pitch at a lower pulse energy. The decrease with increasing pitch can be explained by the decrease in deposited pulse energy per unit length. In contrast, the etched length decreased with decreasing pitch in $\mathrm{H}_{2} \mathrm{SO}_{4}$, with the highest pulse energy of $2.0 \mu \mathrm{J}$. Similar unordinary dependence has been observed in sapphire and silica glass $[14,16,17]$, and the origin was

(a)

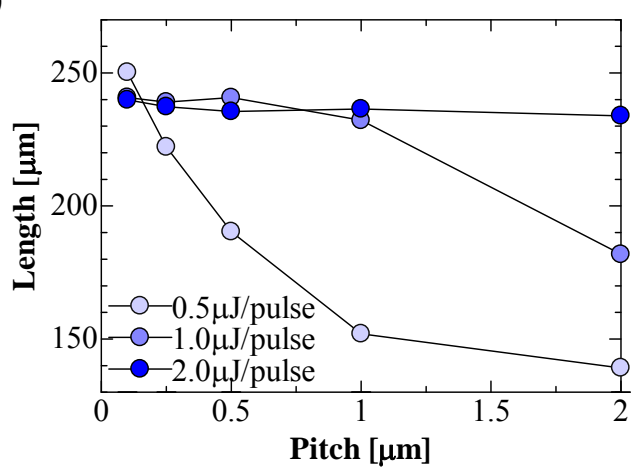

(b)

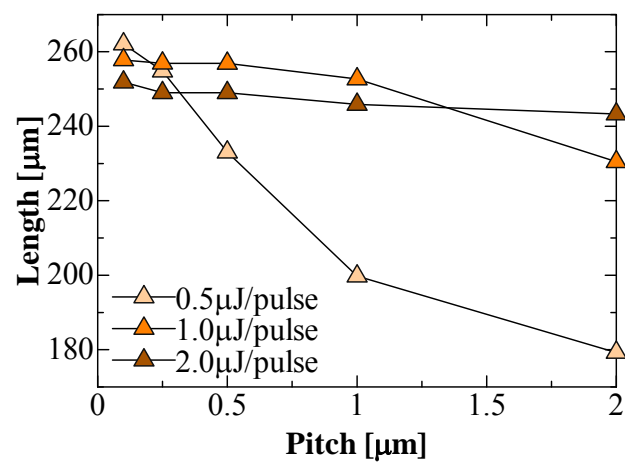

(c)

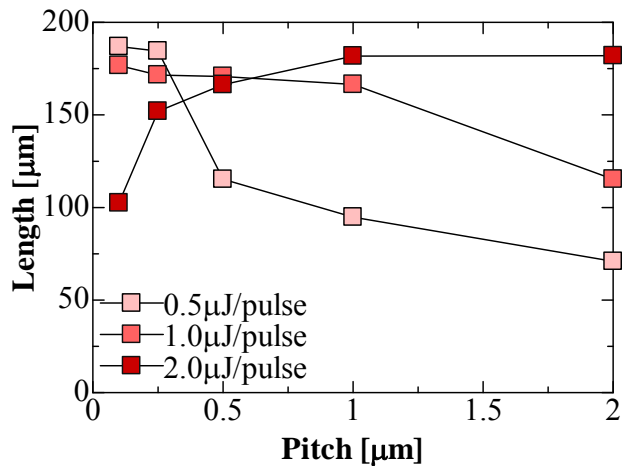

Fig. 4 Etched length as a function of pitch. The etchants were (a) $\mathrm{HCl}$, (b) $\mathrm{HNO}_{3}$, and (c) $\mathrm{H}_{2} \mathrm{SO}_{4}$, all at a concentration of $0.5 \mathrm{M}$, and the etching period was 26 h. The substrates used were $\mathrm{CaF}_{2}$ (111), and the microchannel was along the $<112>$ direction. 


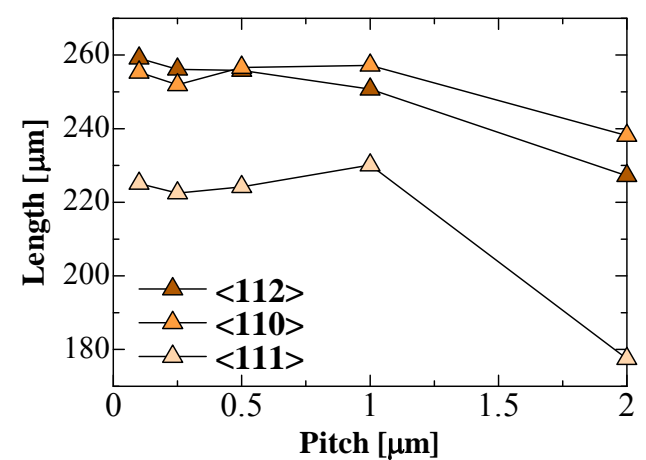

Fig. 5 Etched length along different crystalline axes in $\mathrm{CaF}_{2}$. The etchant was $\mathrm{HNO}_{3}$, and the etching period was $26 \mathrm{~h}$. The pulse energy was $1.0 \mu \mathrm{J}$.

explained in terms of amorphous-to-polycrystalline transition of the modified amorphous region in sapphire. Here, the story may be different because the phenomenon was observed in only one etchant. We speculate that an extra modified region, where the etching rate was sensitive to the etchant, was fabricated in the outer region under high pulse energy and short pitch conditions, and extra broadening of the microchannel impeded elongation of the etched length.

We compared the etching rate along modified lines of $<112\rangle,\langle 111\rangle$, and $<110\rangle$ directions. Figure 5 shows the results with $\mathrm{HNO}_{3}$ etchant. Roughly, the etching rates along the $<112\rangle$ and $<110\rangle$ directions were similar, and that along the $<111>$ direction was the lowest, about 75 $90 \%$ of the others. This dependence may be related to the cleavage property of $\mathrm{CaF}_{2} ;\{111\}$ is the cleavage plane.

In the case of a strong pulse energy and short pitch, the outline of the microchannel was burr-shaped, as shown in Fig. 6. As seen, there are small protuberances in the outer shell of the microchannel. The protuberances have directionality, and the direction was independent of the direction of etching but dependent on the direction of fs laser writing. This result indicates that the origin of burr-shape should be attributed to some effect during fs laser modification. One speculation for this is a quasi-periodic accumulationrelease cycle of stress.

It is important to determine why selective etching around the modified lines occurs in $\mathrm{CaF}_{2}$. We speculate that the factors that increase the etching rate include amorphization, which has been observed in sapphire [14] and quartz [2], and stress, which was mentioned in the previous paragraph. To clarify the origin of selective etching, we conducted a transmission electron microscopy (TEM) experiment to observe structural change. We found that TEM

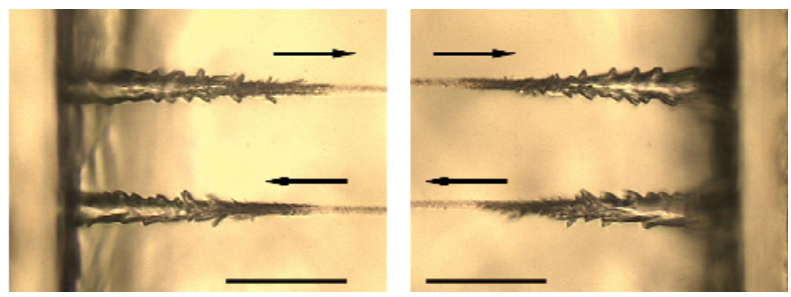

Fig. 6 "Burr"-shaped microchannels. The substrates used were $\mathrm{CaF}_{2}(110)$, and the direction of the modified lines was along the $<111>$ direction. The irradiated pulse energy was $2.0 \mu \mathrm{J}$, and the pitch was 0.1 $\mu \mathrm{m}$. The etchant was $0.5 \mathrm{M} \mathrm{H}_{2} \mathrm{SO}_{4}$. The arrows show the direction of fs laser writing. Scale bars, $70 \mu \mathrm{m}$. (a1)

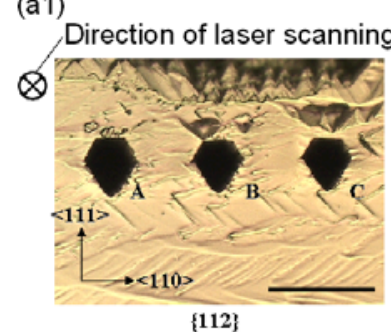

(a2)

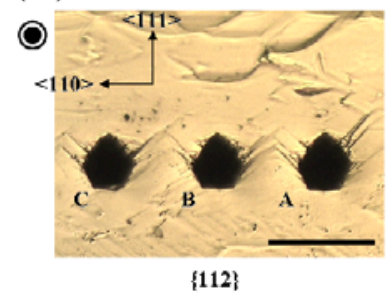

(b1)

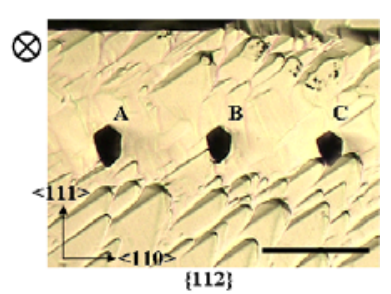

(b2)

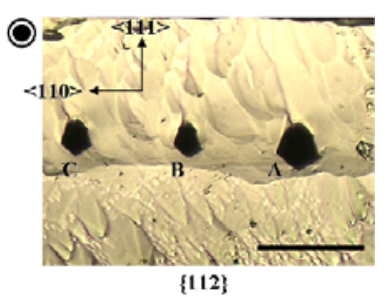

Fig. 7 Optical micrographs of the inlet of the microchannel on the end facet, (a) etched in $\mathrm{HNO}_{3}$, and (b) etched in $\mathrm{H}_{2} \mathrm{SO}_{4}$. (a1) and (a2), as well as (b1) and (b2), show opposite ends of the microchannel. Scripts "A," "B," and " $\mathrm{C}$ " indicate the same microchannel in (a1) and (a2) as well as (b1) and (b2). Scale bars, $70 \mu \mathrm{m}$.

observation of $\mathrm{CaF}_{2}$ is difficult with our TEM, because $\mathrm{CaF}_{2}$ was easily resolved by irradiation with an electron beam at room temperature. A TEM equipped with a cooling stage will enable us to observe structural change around the modified region. This is left for a future study.

We observed the shape of the microchannel inlet on the end facets, as shown in Fig. 7. As the figure reveals, the shapes of the inlets were polygonal rather than rounded. The polygonal shape indicates that the etching rate around the modified region was not isotropic but anisotropic. Anisotropic etching of $\mathrm{CaF}_{2}$ by these etchants has been reported [18]. The shape was different between two etchants. In addition, comparing opposite end facets (e.g., the comparison between (a1) and (a2)), the shape was reversed with respect to the $<111>$ direction. We suppose that anisotropic etching depending on the crystalline axis occurred around the modified region, and the dependency was different between the two etchants, but we could not identify which crystalline plane was etched faster or which was etched less. In addition to the end facets, a geometric pattern was observed after etching on the top and bottom surfaces of the substrates. This may also be related to the different etching rate depending on the crystalline axis.

\section{Conclusions}

Femtosecond laser-assisted etching was examined in $\mathrm{CaF}_{2}$ and $\mathrm{MgF}_{2}$ crystalline substrates with etchants of $\mathrm{HNO}_{3}, \mathrm{H}_{2} \mathrm{SO}_{4}$, and $\mathrm{HCl}$. For $\mathrm{CaF}_{2}$, selective etching with a selectivity of about 20 was observed. The etching rate around the modified region was anisotropic. In contrast, no signature of etching was observed for $\mathrm{MgF}_{2}$.

\section{Acknowledgments}

This research was partly supported by KAKENHI (20360115) and a Research for Promoting Technological Seeds (13-024) grant from the Japan Science and Technology Agency. 


\section{References}

[1] R.R. Gattass and E. Mazur: Nature Photonics, 2, (2008) 219.

[2] S. Matsuo, Y. Tabuchi, T. Okada, S. Juodkazis, and H. Misawa: Applied Physics A 84, (2006) 99.

[3] Y. Kondo, J. Qiu, T. Mitsuyu, K. Hirao, and T. Yoko: Japanese Journal of Applied Physics, 38, (1999) L1146.

[4] A. Marcinkevičius, S. Juodkazis, M. Watanabe, M. Miwa, S. Matsuo, H. Misawa, and J. Nishii: Optics Letters, 26, (2001) 277.

[5] Y. Cheng, K. Sugioka, and K. Midorikawa: Opt. Lett., 29, (2004) 2007.

[6] N. Bellini, K. C. Vishnubhatla, F. Bragheri, L. Ferrara, P. Minzioni, R. Ramponi, I. Cristiani, and R. Osellame: Optics Express, 18, (2010) 4679.

[7] S. Rajesh and Y. Bellouard, Optics Express: 18, (2010) 21490.

[8] Z. Wang, K. Sugioka, and K. Midorikawa: Applied Physics A, 89, (2007) 951.

[9] Y. Hanada, K. Sugioka, H. Kawano, I. Shihira Ishikawa, A. Miyawaki, and K. Midorikawa: Biomedical Microdevices, 10, (2008) 403.

[10] S. Matsuo, S. Kiyama, Y. Shichijo, T. Tomita, S. Hashimoto, Y. Hosokawa, and H. Masuhara: Applied Physics Letters, 93, (2008) 051107.
[11]A. B. Bel'skiı̌, M.A. Gan, I.A. Mironov, and R.P. Seřsyan: Journal of Optical Technology, 76, (2009) 496.

[12] J. Wang, M.J. D'lallo, S. VanKerkhove, and H. Schreiber: Proc. 2010 OSA Topical Meeting on Optical Interference Coatings: Measurement Problem, (2010) MD7.

[13] C. Hnatovsky, R. Taylor, E. Simova, P. Rajeev, D. Rayner, V. Bhardwaj, and P. Corkum: Appl. Phys. A 84, (2006) 47.

[14] S. Juodkazis, K. Nishimura, H. Misawa, T. Ebisui, R. Waki, S. Matsuo, and T. Okada: Advanced Materials, 18, (2006) 1361.

[15] S. Matsuo, H. Sumi, S. Kiyama, T. Tomita, and S. Hashimoto: Appl. Surf. Sci., 255, (2009) 9758.

[16] S. Rajesh and Y. Bellouard: Opt. Express, 18, (2010) 21490.

[17]X. Yu, Y. Liao, F. He, B. Zeng, Y. Cheng, Z. Xu, K. Sugioka, and K. Midorikawa: J. Appl. Phys. 109, (2011) 053114.

[18] C. Motzer and M. Reichling: Journal of Applied Physics, 105, (2009) 064309 .

(Received: June 13, 2011, Accepted: December 07, 2011) 